\title{
Central Adiposity, Body Mass Index and Percent Body Fat among Bengalee Hindu Male Slum Dwellers of Dum Dum, West Bengal, India
}

\author{
Raja Chakraborty ${ }^{1,2}$ and Kaushik Bose ${ }^{*, 2}$ \\ ${ }^{I}$ Dinabandhu Mahavidyalaya, Bongaon, West Bengal, India \\ ${ }^{2}$ Department of Anthropology, Vidyasagar University, Midnapore, West Bengal, India
}

\begin{abstract}
The relationship between body mass index (BMI) and percent body fat (PBF) with central adiposity measures varies between ethnic groups and it has not been much studied in low socio-economic groups in India. Therefore, this study was undertaken to test the relative efficacy of waist circumference (WC), hip circumference (HC), waist hip ratio (WHR) and conicity index (CI) to predict BMI and PBF among Bengalee Hindu male slum dwellers. A total of 465 adult (aged 18-72 years) male slum dwellers of Bengalee Hindu ethnicity were included. Standard anthropometric techniques and formulae were used. WC showed the strongest significant $(\mathrm{p}<0.001)$ partial correlation with BMI and PBF $(0.82$ and 0.77 , respectively). Stepwise multiple linear regression analyses of BMI and PBF with the central adiposity measures revealed that WC had the strongest impact on BMI and PBF. On the other hand WHR, HC and CI had weaker effect. Moreover, WC alone accounted for about 67 and 60 per cent of the variations, respectively, of BMI and PBF. The models involving only WC and CI, explained almost similar proportions of variations ( $\operatorname{adj} R^{2}=94.1$, and 69.4, respectively). Furthermore, the WC was found to best predict BMI $\left(R^{2}\right.$ Change $=0.666 ; F$ Change $\left.=921.32, \mathrm{p}<0.001\right)$ and $\mathrm{PBF}\left(R^{2}\right.$ Change $=0.597 ; F$ Change $=686.66, \mathrm{p}<0.001$ ). Even after controlling for each other, i.e., BMI and PBF (results not shown) WC had the strongest significant impact on these two measures. Therefore, in this population, WC may be preferred over other measures of central adiposity in studies dealing with obesity and cardio vascular disease risk factors.
\end{abstract}

Keywords: Bengalee, central adiposity, body mass index, percent body fat.

\section{INTRODUCTION}

Body mass index (BMI) is a measure of overall adiposity, whereas, waist circumference (WC), waist-hip ratio (WHR), and conicity index (CI) are reliable proxy measures of abdominal fat $[1,2]$. Studies indicate that BMI, WC and WHR could be used independently to identify overweight and obesity [3]. These measures of adiposity have also been widely recommended for epidemiological surveys because of their independent association with major cardiovascular and metabolic risk factors. However, there is little consensus as to which of these measures is preferable in studies dealing with abdominal adiposity [4-6]. It is also not clear which of these measures best predicts total body fat [7]. Therefore, it seems important to understand the relationship of these central adiposity measures with generalized adiposity and body fat content because BMI and the total body fat as well as its distribution pattern are related to metabolic syndrome [8]. The interrelationship of WC with WHR and BMI is also required to be understood to identify not only those who have high BMI, but also those who have low BMI but high WHR by using the simple measure of WC [9]. Higher BMI has also been shown to be associated with both central adiposity and higher WHR along with the noncommunicable diseases that appear at lower BMI ranges in Indian population [10]. It is also desirable to have a

*Address correspondence to this author at the Department of Anthropology, Vidyasagar University, Midnapore - 721 102, West Bengal, India;

E-mail: banda@vsnl.net measurement simpler than BMI and PBF but at the same time being a good predictor of the later two. It is most important, especially, for the fast and effective implementation of public health development programmes in limited resource set ups.

Asian Indians, in common, were reported to have mean and median values of BMI lower than that observed in nonAsians, and also have higher PBF, waist-to-hip ratio (WHR) and abdominal fat at a lower level of BMI [11-13] and also a higher susceptibility to diabetes mellitus (DM) and insulin resistance compared with the Europeans $[14,15]$. On the other hand, central adiposity has been linked to increased risk of cardiovascular disease, hypertension and diabetes by many studies [16-18]. There are many studies in Indian populations dealing with central adiposity and cardiovascular risk factors [19-22] and diabetes [23, 24]. But little attempts have been made $[6,7,9,25]$ to identify the best abdominal measure to predict BMI and PBF. However, the terms Asian Indians and Indian represent vast and bio-culturally diverse populations at different degrees of urbanization, socioeconomic and nutritional histories [26]. Therefore, it may be of particular interest to study the relationships between overall and regional adiposity in these different sub-groups.

The relationship between BMI and other adiposity measures were studied mostly in higher socio-economic groups [27-29]. But this is not well documented in lower socioeconomic groups [30]. Recent studies also documented that cardiovascular disease (CVD) was a major health problem among the Bengalee ethnic group [31,32]. Therefore, in 
this study, an attempt has been made to test the relative efficacy of WC, hip circumference (HC), WHR and CI to predict BMI and PBF among Bengalee Hindu male slum dwellers of Kolkata, India.

\section{MATERIALS AND METHODOLOGY}

\section{The Study Area and the Population}

This study is based on a cross sectional survey carried out as part of a research project undertaken jointly by the authors. All the subjects were adult male individuals aged 18 years or above and residents of a slum named 'Bidhan Colony', situated approximately $15 \mathrm{kms}$ from Kolkata (formerly Calcutta) town centre. Kolkata is the capital city of West Bengal province. Most of the subjects had migrated from Bangladesh as well as from other districts of the West Bengal province. The slum is situated at the right hand side of the railway tracks between Dum Dum Junction and The Dum Dum Cantonment Railway Stations. It is the terminal part of an urban settlement, called East Sinthee nearby to the Dum Dum Junction Rly. Station, and under The South Dum Dum Municipality, P.S.- Dum Dum, North 24 Parganas, West Bengal, India. At the other side of the said railway track is area under Kolkata Corporation.

All the participants had their origin in the state of West Bengal and spoke Bengali language as the mother tongue. They belonged to the Hindu religious group. A total of 474 reportedly healthy males, without having any known disease, not under any prolonged medication, not having undergone any recent surgery and able to do their normal day-to-day works at the time of examination, participated in the study. This sample size was enough to test all hypotheses at $5 \%$ level of significance with power $80 \%$ (beta $=0.8$ ). Out of these, data on 465 individuals are presented in the present analysis, since nine individuals were aged more than 72 years and thus their body composition could not be estimated using available validated equation [33]. Most of the people were engaged in so called jobs of low socio-economic status, ranging from factory workers to rickshaw-pullers, or, daylabourers. There were landlords who are the first settlers of the locality, and also a huge number of families tenants to them. The general hygienic condition clearly seemed to be poor. The sanitation, sewerage systems and household structures were the silent but definite indications of their poverty and poor quality of life.

\section{Data Collection}

Ethical approval and prior permission was obtained from Vidyasagar University Ethics Committee and the institution of the first author, respectively. The municipal authorities and local community leaders were informed before commencement of the study. Most households were approached in the evening, because of the greater likelihood of adult males being present. Occasionally, prior appointments were made at the time with individuals for interviews to be carried out on a subsequent visit. Most of the subjects were interviewed and measured at their respective households. However, in some cases, where logistical issues made it difficult to carry out the survey in the respective households of some subjects, they were taken to a common place where a number of them were examined together. However, care was taken so that all the participants resided inside the boundary of the slum under study, i.e., Bidhan Colony. The overall response rate was around $80 \%$. Informed consent was also obtained from each participant before starting interviews. The field investigation including anthropometric measurements was done by the first author (RC). Primary information on ethnicity, age, monthly family income (MFI), number of family members (FM), occupation, and education were collected from each subject with the help of a pretested questionnaire. Income was recorded in Indian rupee (UK $£ 1=80$ Indian Rupees, approx). Monthly per capita income (MPCI) was calculated as MFI divided by FM. Occupation was graded as manual and non-manual.

\section{Anthropometric Measurements}

All the measurements were taken following the standard techniques [34]. Height and weight were measured to the nearest $0.1 \mathrm{~cm}$ and $0.5 \mathrm{~kg}$, respectively, using a local made Martin's type anthropometer, and standard weight scale, respectively. Minimum waist (WC) and maximum hip (HC) circumferences were measured to the nearest $0.1 \mathrm{~cm}$ using a tape measure (Triced, Sanghai, Chaina). Four skin folds namely, biceps (BSF), triceps (TSF), sub-scapular (SSF) and supra-iliac (SISF), were measured to the nearest $0.2 \mathrm{~mm}$ using a skin fold calliper (Holtain Ltd., UK). Technical errors of measurements were found to be within acceptable limits [35] and therefore, were not incorporated in the analyses. The BMI, WHR, and Conicity Index [36] were computed using the following standard equations:

BMI $\left(\mathrm{kg} / \mathrm{m}^{2}\right)=$ weight $(\mathrm{kg}) /$ height $\left(\mathrm{m}^{2}\right)$.

$\mathrm{WHR}=\mathrm{WC}(\mathrm{cm}) / \mathrm{HC}(\mathrm{cm})$

$\mathrm{CI}=\operatorname{MWC}(\mathrm{cm}) /(0.109) \times \sqrt{ }$ [weight $(\mathrm{kg}) /$ height $(\mathrm{m})$

Per cent Body Fat (PBF) was calculated using four skin folds with the following standard equations [33] already validated in Indian population [37] and has been utilized to estimate body composition among the Bengalee ethnic group by recent studies $[7,38]$. The equations used were:

Density $=1.1356-0.07 \times \log _{10}(\mathrm{BSF}+\mathrm{TSF}+\mathrm{SSF}+\mathrm{SISF})$.

$\mathrm{PBF}=(4.95 /$ density-4.5) $\mathrm{x} 100$

The subjects were classified as underweight, overweight and obese if they have BMI $<18.5, \mathrm{BMI} \geq 23 \mathrm{~kg} / \mathrm{m}^{2}$ and BMI $\geq 25 \mathrm{~kg} / \mathrm{m}^{2}$ (WHO, 2000) [39] abdominal adiposity by WC, as normal (WC $\leq 80 \mathrm{~cm}$ ) and obese (WC $>80 \mathrm{~cm}$ ) [9]. Excess adiposity was determined as $\mathrm{PBF}>25 \%$ [40].

\section{Analyses of Data}

The distributions of the anthropometric variables were not significantly skewed. Age and anthropometric variables were described by their means and standard deviations. Multiple linear regression analysis was carried out to show the effect of central adiposity on BMI and PBF. Pearson correlation coefficients were calculated to see the relations of anthropometric parameters with MFI and MPCI. Partial correlation coefficients were computed, after controlling for age to show the relative associations of BMI with WC, WHR and CI. The subjects were further divided into the following age groups: 18-29.9 $(\mathrm{n}=173,37.2 \%), 30-39.9(\mathrm{n}=113$, $24.3 \%), 40-49.9(\mathrm{n}=97,20.9 \%), 50-59.9(\mathrm{n}=52,11.2 \%)$ 
and 60-72.0 $(\mathrm{n}=30,6.5 \%)$ years to test whether these relationships vary across age groups. All statistical analyses were undertaken using the SPSS Statistical Package, version 10.0. Statistical significance was set at $p<0.05$.

\section{RESULTS}

A total of $65.2 \%$ of the subjects had manual occupation, and the rest $(34.8 \%)$ had non-manual jobs. Regarding educational status, $28.6 \%$ of them were illiterate or only could sign their names and never went to school, $31.4 \%$ did not pass eighth standard, 34\% had secondary level education and $3.96 \%$ had passed twelfth standard. Only $1.9 \%$ had earned graduate degree or did not pass the undergraduate level. The means and standard deviations of age, anthropometric and socio-economic variables are presented in Table 1. The mean (range) age of the subjects was 36.7 (1872) years. Mean (sd) MFI and MPCI were Rs. 3654.4 (1971.0) and Rs. 885.3 (502.2), respectively.

Table 1. Characteristics of the Sample $(n=465)$

\begin{tabular}{|c|c|c|}
\hline Variables & Mean & SD \\
\hline \hline Age (years) & 36.7 & 13.2 \\
\hline MFI (Rs) & 3654.4 & 1971.0 \\
\hline MPCI (Rs) & 885.3 & 502.2 \\
\hline Height $(\mathrm{cm})$ & 161.5 & 6.2 \\
\hline Weight $(\mathrm{kg})$ & 53.1 & 9.5 \\
\hline BSF $(\mathrm{mm})$ & 4.4 & 2.4 \\
\hline TSF $(\mathrm{mm})$ & 7.2 & 3.5 \\
\hline SSF $(\mathrm{mm})$ & 13.6 & 7.6 \\
\hline SISF $(\mathrm{mm})$ & 13.0 & 8.7 \\
\hline PBF $(\%)$ & 15.8 & 7.0 \\
\hline BMI $\left(\mathrm{kg} / \mathrm{m}^{2}\right)$ & 20.3 & 3.3 \\
\hline WC $(\mathrm{cm})$ & 74.0 & 9.2 \\
\hline HC $(\mathrm{cm})$ & 84.1 & 7.7 \\
\hline WHR & 0.89 & .17 \\
\hline CI & 1.19 & .08 \\
\hline
\end{tabular}

Overall, $31.8 \%, 11.6 \%$ and $8.0 \%$ of the subjects were underweight $\left(\mathrm{BMI}<18.5 \mathrm{~kg} / \mathrm{m}^{2}\right.$ ) overweight $(\mathrm{BMI} \geq 23$ $\mathrm{kg} / \mathrm{m}^{2}$ ) and obese $\left(\mathrm{BMI} \geq 25 \mathrm{~kg} / \mathrm{m}^{2}\right), 23 \%$ were found to be abdominally obese (WC $>80 \mathrm{~cm}$ ), and only $9 \%$ were found to be obese by WHR (WHR > 0.95). $13.5 \%$ of the subjects were found to be obese by percent body fat (PBF $>25.0 \%)$. Age was not significantly correlated with either BMI or PBF. Correlation studies revealed that (results not presented) both MFI and MPCI had significant associations with all the anthropometric variables except for height, WHR and CI. Table 2 shows Partial correlation coefficients of WC, WHR, and $\mathrm{CI}$ with $\mathrm{BMI}$ and $\mathrm{PBF}$. WC showed the strongest significant $(\mathrm{p}<0.001)$ partial correlation with $\mathrm{BMI}$ and $\mathrm{PBF}$ ( 0.82 and 0.77 , respectively). $\mathrm{HC}$ was also found to be significantly correlated with BMI $(r=0.67 ; \mathrm{p}<0.001)$ and
PBF $(r=0.66 ; \mathrm{p}<0.001)$. On the other hand, WHR and CI had much weaker partial correlations with BMI and PBF. It may be mentioned here that these values remained almost the same when age, MFI, and MPCI were controlled for. There were also no significant differences (results not presented) in these relationships across age groups.

Table 2. Partial Correlation Coefficients of Central Adiposity Measures with BMI and PBF after Controlling for Age, MFI and MPCI

\begin{tabular}{|c|c|c|}
\hline Variables & BMI & PBF \\
\hline \hline WC & $0.82^{*}$ & $0.77^{*}$ \\
\hline HC & $0.68^{*}$ & $0.67^{*}$ \\
\hline CI & $0.32^{*}$ & $0.41^{*}$ \\
\hline WHR & $0.19^{*}$ & $0.15^{*}$ \\
\hline${ }^{\mathrm{p}}<0.001$ &
\end{tabular}

Stepwise multiple linear regression analyses for BMI (Table 3) and PBF (Table 4), separately, on the central adiposity measures revealed that $\mathrm{WC}$ had the strongest impact on both BMI (Table 3) as well as PBF (Table 4). On the other hand, WHR, HC and CI had weaker effects on each. The regression equations, involving all the four central adiposity measures entered together, predicted around $94 \%$ and $71 \%$ of the total variability of $\mathrm{BMI}$ and $\mathrm{PBF}$, respectively. On the other hand, models involving only $\mathrm{WC}$ and CI (excluding HC and WHR), explained almost similar proportions of variations of BMI $\left(\right.$ adj $\left.R^{2}=94.1\right)$, and PBF (adj $\left.R^{2}=69.4\right)$, respectively. Furthermore, the WC was found to best account for the variability of BMI $\left(R^{2}\right.$ Change $=0.666 ; F$ Change $=921.322, \mathrm{p}<0.001)$ and PBF $\left(R^{2}\right.$ Change $=0.597 ; F$ Change $=2149.587, \mathrm{p}<0.001)$. Even after controlling for each other, i.e., BMI and PBF (results not shown), WC had strongest significant impact on these two measures compared with WHR and CI. It is also worth mentioning that these relationships did not differ across the age groups.

\section{DISCUSSION}

The BMI is widely used as a surrogate measure of overall adiposity because of its simplicity and high correlation with PBF [41, 42]. But the relationship of BMI with PBF and central adiposity depends upon age, sex and ethnic background [43-46]. However, the accumulation of body fat in the abdominal region is now established to be more predictive of health risks than in other regions of body or overall adiposity as measured by BMI $[47,48]$. BMI, WHR, and $\mathrm{WC}$ all have been shown to have significant role in identification of obese and overweight individuals [3]. BMI is a measure of overall adiposity and the Asian Indians tend to have comparatively more body fat and its centralised deposition at a lower level of BMI [12]. It is also not clear which of the central adiposity measures best predict the overall adiposity [6,7]. Therefore, the objective of the present study was to find out the most effective and simple anthropometric measure of abdominal adiposity to predict BMI as well as PBF. 
Table 3. Stepwise Multiple Linear Regressions of BMI and Central Adiposity Measures

\begin{tabular}{|c|c|c|c|c|c|c|}
\hline Predictors & $B$ & $\mathrm{se} B$ & Beta & $T^{*}$ & F-Change & $\mathbf{R}^{2}$ Change \\
\hline WC & 0.586 & 0.016 & 1.654 & 37.77 & $921.32 * *$ & 0.666 \\
\hline $\mathrm{HC}$ & -0.074 & 0.015 & -0.174 & -4.95 & $5.928^{*}$ & 0.001 \\
\hline WHR & -2.114 & 0.493 & -0.111 & -4.29 & $18.411 * *$ & 0.002 \\
\hline
\end{tabular}

Table 4. Stepwise Multiple Linear Regressions of PBF and Central Adiposity Measures

\begin{tabular}{|c|c|c|c|c|c|c|}
\hline Predictors & $B$ & se $B$ & Beta & $T^{*}$ & F-Change & $R^{2}$ Change \\
\hline WC & 0.560 & 0.075 & 0.744 & 7.477 & $686.66^{* *}$ & 0.597 \\
\hline $\mathrm{HC}$ & -0.330 & 0.072 & 0.366 & 4.569 & $15.08 * *$ & 0.010 \\
\hline WHR & -7.425 & 2.378 & 0.183 & 3.123 & $9.75^{*}$ & 0.006 \\
\hline
\end{tabular}

In our study WC explained the highest variability of both BMI and PBF compared with WHR and CI. In other studies also WC performed the best to assess intra abdominal fat in contrast to subcutaneous fat $[49,50]$. WC has been also reported to predict most closely the total body fat [51]. In a study among adolescents [5] BMI and WC have been identified as diagnostic for fatness, while WHR has been less useful. In another recent study [6] among Bengalee Hindu elders (aged $\geq 55$ ), $\mathrm{WC}$ has been found to be most correlated with BMI than WHR or CI, and BMI explain the highest variability of WC than of WHR and CI in both men and women. In the present study the contribution of WC, WHR and $\mathrm{CI}$ has been evaluated among the adult Bengalee males. WC had been found to be most strongly correlated with BMI and the later explained the largest variability of it. A study among groups of low socio-economic status from the southern part of India provided evidence that BMI, WHR and CI, all had significant inter-correlations and both the later measures were influenced by BMI [30].

A study from India [25] also concluded that WC correlated better with BMI than WHR. But they did not study CI. Another recent study [7] among adult females in the Bengalee population found that WC had the highest correlation with total body fat and explained the largest amount of variation in the same measure. In the same study, CI was a relatively better index compared to WHR to predict total body fat. There are other studies also in which WC had better efficacy in detecting overweight than WHR [52] and BMI [53]. The present study was also in conformity with this study in the same population but in adult males, showing the highest partial correlation between PBF and WC. As it is always more desirable to have the simplest and inexpensive measure for the use in the field situation and for emergency clinical diagnosis, WC seems to have the highest potential in this regard. Like the study mentioned above [6], we found that $\mathrm{CI}$ had better correlation with BMI as well as with PBF as compared to WHR. Our results perhaps, simply indicate that a great proportion of the body fat (which has its contribution to BMI) is located in the abdomen in these males. Therefore, most of the BMI variation is accounted for by the WC. Moreover, if it is assumed that WC reflects more of the fat mass than the muscle mass, then it can be proposed that BMI values of these males represent more fat than muscles. This has also support for many studies which earlier showed that the South Asians have more body fat at same BMI than the Europeans.

\section{CONCLUSION}

In conclusion, we propose that, $\mathrm{WC}$, which has been already recommended for use in health promotion or primary care $[54,55]$ may be preferred over other measures of central adiposity in assessment of obesity, in this population, However, with this proposal, some of the obvious limitations of the study must be mentioned. Firstly, no so called gold standard measures of body fat, such as, DXA, BII, or CT were used because they are relatively costly and not easy or sometimes impossible to carry out in the field situations in epidemiological surveys. Therefore, the well recommended and population validated [33, 37] equations using simpler skinfold measures were utilized to assess PBF. Secondly, no measures of metabolic variables associated with CVD and DM were taken in this study. Further studies in this section of the population are needed to unravel the relative associations of these variables with central adiposity measures, especially, with WC.

\section{ACKNOWLEDGEMENTS}

All subjects who participated in the study are gratefully acknowledged. This work was partly funded by the 
University Grants Commission (India) Minor Research Project Grant Number PSW054/03-04 ERO awarded to RC. The authors acknowledge the kind co-operation of Atul Dhali, Gopal Das and Swapan Mallik of Bidhan Colony.

\section{CONFLICT OF INTEREST}

The authors solemnly confirm that there are no relevant associations that might cause any conflict of interest.

\section{REFERENCES}

[1] Bose K, Mascie-Taylor CGN. Conicity index and waist-to-hip ratio and their relationship with total cholesterol and blood pressure in middle aged Europeans and migrant Pakistani men. Ann Hum Biol 1998; 25: 11-16.

[2] Kopelman PG. Obesity as a medical Problem. Nature 2000; 404: 635-43.

[3] Gill T, Chittlebourough C, Taylor A, et al. Body mass index, waist hip ratio and waist circumference: which measure to classify obesity? Soz Preventivemed 2003; 48: 191-200.

[4] Dalton M, Cameron AJ, Zimmet PZ, et al. AusDiab Steering Committee. Waist circumference, Waist-hip ratio and body mass index and their correlation with cardiovascular disease risk factors in Australian Adults. J Int Med 2003; 254: 555-563.

[5] Neovious M, Linne Y, Rossner S. BMI, waist circumference and waist-hip ratio as diagnostic tests for fatness in adolescents. Int $\mathrm{J}$ Obes 2005; 29:163-9.

[6] Bose K. Which measure of abdominal adiposity best relates with body mass index among older Bengalee Hindus of Kolkata, India? A comparison of three measures. Int J Anthropol 2006; 21: 247-52.

[7] Ghosh JR, Bandyopadhyay AR. Waist circumference as a measure of total body fat in Asian Indians. Int J Body Comp Res 2007; 5(3): 89-93.

[8] Lev-Ran, A. Human Human Obesity: an evolutionary approach to understand our bulging waist line. Diabetes Metab Res Rev 2001; 17: 347-62.

[9] Dasgupta S, Hazra SC. The utility of waist circumference in assessment of obesity. Ind J Public Health 1999; 43: 132-5.

[10] Yajnik CS. Commentary: fetal origins of cardiovascular risk: nutritional and non-nutritional. Int J Epidemiol 2001; 30: 57-9.

[11] Deurenberg-Yap M, Schmidt G, van Stavaren WA, Deurenberg P. The paradox of low body mass index and high body fat percentage among Chinese, Malaya and Indians in Singapore. Int J Obes 2000; 24: 1011-7.

[12] Dudeja V, Mishra A, Pandey RM, et al. BMI does not accurately predict overweight in Asian Indians in Northern India. Br J Nutr 2001; 86: 105-12.

[13] Deurenberg P, Deurenberg-Yap M, Guricci S. Asians are different from Caucasians and from each other in their body mass index / body fat per cent relationship. Obes Rev 2002; 3: 141-6.

[14] McKeigue PM, Shah B, Marmot MG. Relation of central obesity and insulin resistance with high diabetes prevalence and cardiovascular risk in South Asians. Lancet 1991; 337: 382-6.

[15] Wild S, Roglic G, Green A, et al. Global prevalence of diabetes: estimates for the year 2000 and projections for 2030. Diabetes Care 2004; 27: 1047-53.

[16] Venkataramana P, Reddy PC. Association of overall and abdominal adiposity with coronary heart disease factors: comparison between urban and rural men. Asia Pac J Clin Nutr 2002; 11: 68-71.

[17] Grievink L, Alberts JF, O'Niel J, Gerstenbluth I. Waist circumference as a measurement of obesity in the Netherlands Antilles; associations with hypertension and diabetes mellitus. Eu J Clin Nutr 2004; 58: 1159-65.

[18] Wang Y, Rimm FB, Stampfer MJ, et al. Comparison of abdominal adiposity and overall obesity in predicting risk of type-2 diabetes among men. Am J Clin Nutr 2005; 81: 555-63.

[19] Gupta R, Mehrishi S. Waist-Hip ratio and blood pressure correlation in an urban Indian population. J Indian Med Assoc 1997; 95: 412-415.

[20] Misra A, Pandey RM, Rama Devi J, et al. High prevalence of diabetes, obesity and dyslipidaemia in urban slum population in northern India. Int J Obes 2001; 25: 1722-9.
[21] Deshmukh PR, Gupta SS, Dongre AR, et al. Relationship of anthropometric indicators with blood pressure levels in rural Wardha. Ind J Med Res 2006; 123: 657-64.

[22] Anand K, Shah B, Yadav K, et al. Are the urban poor vulnerable to non-communicable diseases? A survey of risk factors for noncommunicable diseases in urban slums of Faridabad. Natl Med J India 2007; 20: 115-20.

[23] Snehalatha C, Viswanathan V, Ramachandran A. Cut off values for normal anthropometric variables in Asian Indian adults. Diabetes Care 2003; 26: 1380-4

[24] Ramachandran A, Snehalatha C, Vijay V. Low risk threshold for acquired diabetologic factors in Asian Indians. Diabetes Res Clin Pract 2004; 65: 189-95.

[25] Kurpad SS, Tandon H, Srinivasan K. Waist circumference correlates better with body mass index than waist hip ratio in Asian Indians. Natl Med J India (2003)16: 189-92. Comment in: Natl Med J India 2004; 17: 115-6.

[26] WHO Expert Consultation. Appropriate body mass index for Asian populations and its implication for policy and intervention strategies. Lancet 2004; 363: 157-63.

[27] Wardel J, Wrightson K, Gibson, L. Body fat distribution in South Asian women and children. Int J Obes 1996; 20: 267-271

[28] Wellens RI, Roche AF, Khamis HJ, et al. Relationship between body mass index and body composition. Obes Res 1996; 4: 35-44.

[29] Lear SA, Toma M, Birmgham CL, Frolich JJ. Modification of the relationship between simple anthropometric indices and risk factors by ethnic background. Metabolism 2003; 52: 1295-1301.

[30] Kusuma YS, Babu BV, Naidu JM. Chronic energy deficiency in some low socio-economic populations from South India: relationship between body mass index, waist-hip ratio and Conicity index. Homo 2008; 59: 67-79.

[31] Ghosh A, Bose K, Das Chaudhuri AB. Association of food patterns, central obesity measures and metabolic risk factors for coronary heart disease (CHD) in middle-aged Bengalee Hindu men, Calcutta, India. Asia Pac J Clin Nutr 2003;12 (2): 166-171.

[32] Ghosh A, Bose K, Chakravarti S, et al. Relationship of waist circumference and waist-hip ratio with coronary heart disease risk factors among Bengalee Hindu men of Kolkata, India. J R Soc Health 2004; 124 (2): 86-91.

[33] Durnin JVGA, Womersley J. Body fat assessed from total body density and its estimation from skin fold thickness: measurements on 481 men and women aged from 16 to 72 years. Br J Nutr 1974; 32: 77-97.

[34] Lohman TG, Roche AF, Martorell R. Anthropometric standardization reference manual. Chicago:Human Kinetics Books 1998.

[35] Ulijaszek SJ, Kerr DA. Anthropometric measurement error and the assessment of nutritional status. Br. J. Nutr 1999; 82: 165-177.

[36] Valdez R, Seidell JC, Ahn YI, Weiss KM. A new index of abdominal adiposity as an indicator of risk for cardiovascular disease. A cross population study. Int J Obes 1991; 17: 77-82.

[37] Kuriyan R, Petracchi C, Ferro-Luzzi A, et al. Validation of expedient methods for measuring body composition in Indian adults. Indian J Med Res 1998; 107: 37-45.

[38] Bose K, Jana S, Bisai S, et al. Comparison of Nutritional Status Between tuberculosis Patients and Controls: a Study from North 24 Parganas District in West Bengal, India. Mal J Nutr 2007; 13(2): 131-39.

[39] World Health Organization. The Asia Pacific Perspective: Redefining obesity and its treatment. Geneva, Switzerland 2000.

[40] Deurenberg P, Yap MD, Wang J, et al. The impact of body build on the relationship between body mass index and percent body fat. Int J Obes 1999; 23: 537-42.

[41] Norgan NG, Ferro-Luzzi A. Weight-height indices as estimators of fatness in men. Hum Nutr Clin Nutr 1982; 36: 363-72.

[42] Gallagher D, Visser M, Supulveda D, et al. How useful is BMI for comparison of body fatness across age, sex and ethnic groups. Am J Epidemiol 1996; 143: 228-39.

[43] De Lorenzo A, Deurenberg P, Pietrantuono M, et al. How fat is obese? Acta Diabetol 2006; 40: S254-7.

[44] Norgan NG. Body mass index and body energy stores in developing countries. Eur J Clin Nutr 1990; 44 (S1): 79-84.

[45] Taylor RW, Jones IE, Williams SM, Goulding A. Evaluation of waist circumference, waist-to-hip ratio and the Conicity index as screening tools for high trunk fat mass, as measured by dual energy X-Ray absorptiometry, in children aged 3-19 years. Am J Clin Nutr 2000; $72: 490-5$. 
[46] Bose K. The interaction of waist-hip ratio and Conicity index with subcutaneous adiposity in two ethnic groups: native British and migrant Pakistani men. Anthrop Anz 2001; 59:275-82.

[47] Pots J, Simmins D. Sex and ethnic group differences in fat distribution in young United Kingdom South Asians and Europids. J Clin Epidemiol 1994; 47: 837-41.

[48] Despress JP. Intra-abdominal obesity: an untreated risk factor for type 2 diabetes and cardiovascular disease. J Endocrinol Invest 2006; 29: S77-82.

[49] Bjorntorp P. Classification of obese patients and complications related to the distribution of surplus fat. Am J Clin Nutr 1987; 45 (Suppl 5):1120-5.

[50] Seidell JC, Cigolini M, Charzewska J, et al. Fat distribution in European men: a comparison of anthropometric measurements in relation to cardiovascular risk factors. Int J Obes 1992; 16:17-226.
[51] Lean MEJ, Han TS, Deurenberg P. Predicting body composition by densitometry from simple anthropometric measurements. Am J Clin Nutr 1996; 63: 4-14.

[52] Moy FM, Atiya AS. Waist circumference as a screening tool for weight management evaluation using receiver operating characteristic curves for Malay subjects. Asia Pac J Public Health 2003; 15: 99-104.

[53] Molarius A, Seidell JC, Sans S, et al. Waist and hip circumferences and waist-hip ratio in 19 populations of WHO MONIKA Project. Int J Obes 1999; 23: 116-25.

[54] National Institutes of Health (NIH). Clinical guidelines on the identification, evaluation and treatment of overweight and obesity in adults: the Evidence Report1998. Available at www.nhlbi.nih.govt/guidelines

[55] The Scottish Intercillegiate Guidelines Network. Obesity in Scottland: Integrating prevention with weight management. Available at www.sign.ac.uk

(C) Chakraborty and Bose; Licensee Bentham Open.

This is an open access article licensed under the terms of the Creative Commons Attribution Non-Commercial License (http://creativecommons.org/licenses/by$\mathrm{nc} / 3.0 /)$, which permits unrestricted, non-commercial use, distribution and reproduction in any medium, provided the work is properly cited. 